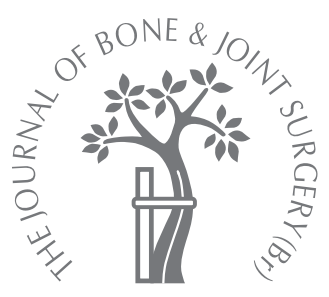

\title{
A custom-made prosthesis attached to an existing femoral component for the treatment of peri- and sub-prosthetic fracture
}

\author{
R. Tillman, \\ S. Kalra, \\ R. Grimer, \\ S. Carter, \\ A. Abudu \\ From the Royal \\ Orthopaedic \\ Hospital, \\ Birmingham, \\ England
}

\footnotetext{
R. Tillman, FRCS, Consultant Orthopaedic Oncology Surgeon

S. Kalra, MRCS, Junior Orthopaedic Surgeon,

Orthopaedic Oncology

- R. Grimer, FRCS, Consultant

Orthopaedic Oncology

Surgeon

S. Carter, FRCS, Consultant

Orthopaedic Oncology

Surgeon

A. Abudu, FRCS, Consultant

Orthopaedic Oncology

Surgeon

Royal Orthopaedic Hospital,

Bristol Road South,

Birmingham, B31 2AP, UK.
}

Correspondence should be sent to Mr R. Tillman; e-mail: roger.tillman@roh.nhs.uk

(C2006 British Editorial Society of Bone and Joint Surgery doi:10.1302/0301-620X.88B10. $17772 \$ 2.00$

$J$ Bone Joint Surg [Br] 2006;88-B:1299-302.

Received 14 February 2006, Accepted after revision 5 June 2006

\begin{abstract}
Peri- and sub-prosthetic fractures, or pathological fractures below an existing well-fixed femoral component, with or without an ipsilateral knee replacement, present a difficult surgical challenge.

We describe a simple solution, in which a custom-made prosthesis with a cylindrical design is cemented proximally to the stem of an existing, well-fixed femoral component. This effectively treats the fracture without sacrificing the good hip. We describe five patients with a mean age of 73 years (60 to 81 ) and a mean follow-up of 47 months (6 to 108).
\end{abstract}

The mean overlap of the prosthesis over the femoral component was $7.5 \mathrm{~cm}$ (5.5 to 10). There have been no mechanical failures, no new infections and no re-operations. We suggest that in highly selected cases, in which conventional fixation is not feasible, this technique offers a durable option and avoids the morbidity of a total femoral replacement.

The number of patients undergoing primary total hip replacement (THR) and hence the incidence of peri-prosthetic disease, continues to rise as the population ages. Numerous reports have documented the increasing incidence of peri-prosthetic fracture, ${ }^{1-3}$ for which conventional treatment includes plating, cerclage wiring, use of the Mennen plate ${ }^{4,5}$ and revision of the femoral component to a longer, cemented or uncemented stem.

A patient who has had ipsilateral total knee and hip replacements poses a major challenge should a subprosthetic fracture occur, particularly when the knee replacement is stemmed. Revision to a long-stemmed THR, proximal femoral replacement, or even total femoral replacement ${ }^{6-8}$ can be undertaken, but these are major procedures and they risk sacrificing an existing stable THR.

Above-knee amputation may be offered to such patients with end-stage prosthetic disease but may be emotionally unacceptable. It also poses a huge physical challenge for a patient, with poor functional results. ${ }^{9}$

We present one solution to this problem, which may be applicable to a small proportion of patients with difficult subprosthetic fractures, and which does not require removal of the existing femoral component if this is functioning well. The technique involves the use of a custom-made hollow cylindrical section which is cemented to the distal aspect of the existing femoral component. Distally, this custom-made cylinder can be connected to the long stem of a revision total knee replacement, or to a diaphyseal replacement. In selected cases, it offers a means of salvaging a challenging situation with less morbidity than the traditional alternatives.

\section{Patients and Methods}

We have used a custom-made femoral-shaft endoprosthesis with a hollow cylindrical section, cemented onto the distal aspect of the existing femoral component in five patients (Figs 1 and 2).

There were three women and two men with a mean age of 73 years (60 to 81). Three fractures were below the stem of the existing THR and were therefore classified as type-C, according to the Vancouver classification. ${ }^{10,11}$ The remaining two were type B1. All the patients were immobile before surgery.

A custom-made prosthesis was manufactured from pre-operative radiological measurements. All implants were made by Stanmore Implants Worldwide (Stanmore, United Kingdom) using a combination of titanium and cobalt-chrome and all the operations were performed by the senior author (RT). In four patients, the endoprosthesis incorporated a rotating hinge knee joint. The present cost of this implant, including both the knee replacement and hydroxyapatite coating, is $£ 4800$ 


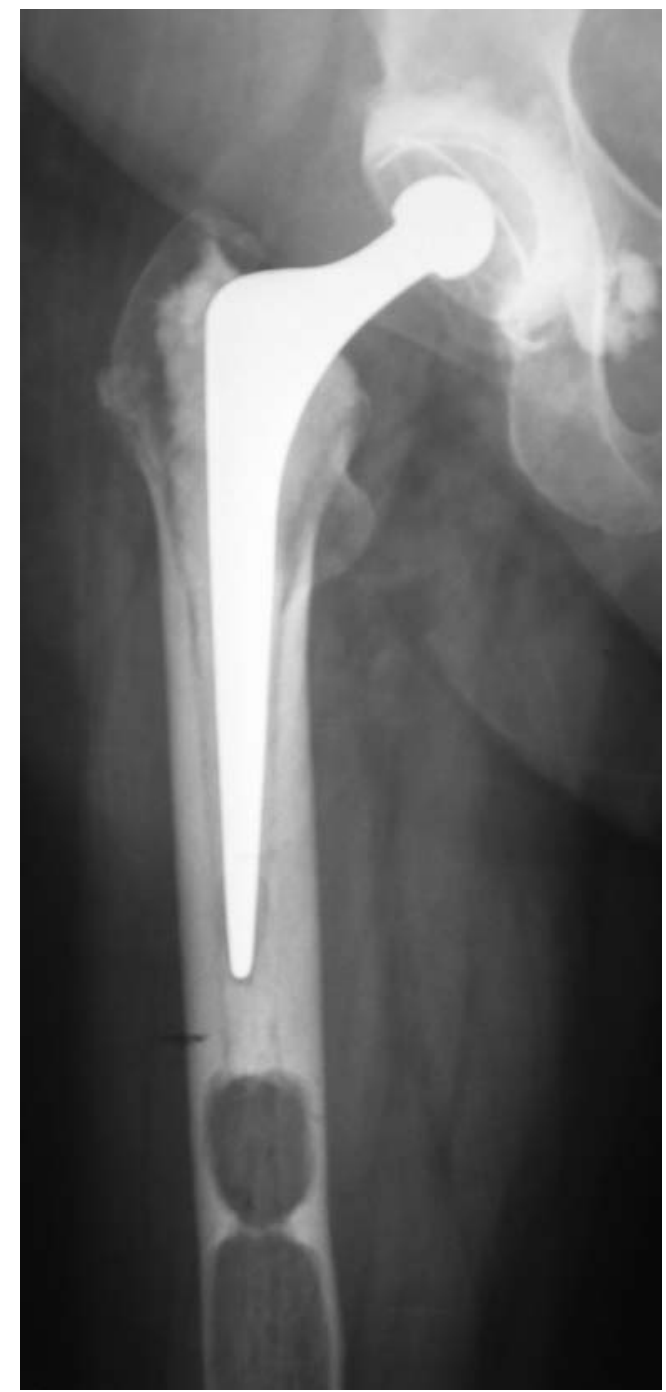

Fig. 1a

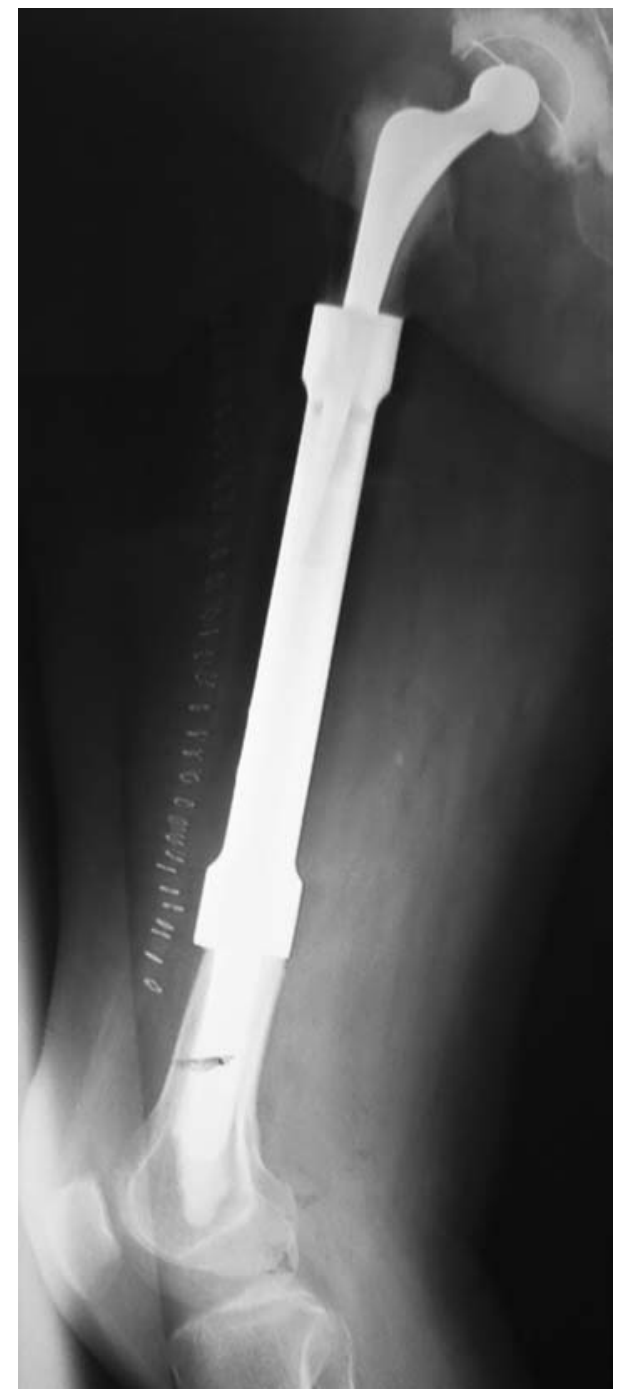

Fig. 1b

Figure 1a - Radiograph of a 75-year-old woman with a lytic subprosthetic lesion (plasmacytoma) which progressed shortly afterwards to a pathological fracture. Figure $1 \mathrm{~b}$ - Post-operative radiograph after resection showing the custom-made cylindrical endoprosthesis connected to the stem of the existing femoral component.

(Stanmore Implants Worldwide). However, if only the shaft of the femur is replaced and not the knee joint, the cost is considerably less (Stanmore Implants Worldwide).

The patients received routine post-operative treatment, as with any major joint replacement. Their details are summarised in Table I.

They were reviewed as out-patients before being transferred back to the referring hospital.

We retrospectively reviewed the notes and radiographs of all five patients. In order to obtain the latest details a telephone survey of all surviving patients was undertaken by the senior author (RT). This provided information regarding mobility, pain and delayed problems such as infection, loosening, and revision surgery.

\section{Results}

The mean per-operative blood loss was 1.51 ( 1 to 2 ) and the mean operating time was two hours (1.5 to 2.5). The mean length of follow-up was 47 months (6 to 108).

The mean overlap of the custom-made endoprosthesis over the femoral component was $7.5 \mathrm{~cm}$ (5.5 to 10) (Table I).

There were no further complications, except for some evidence of loosening around the proximal femoral component in one of the patients. One patient with an infection before surgery continued to have a discharging sinus and one died from metastatic lung cancer two years after the operation. 


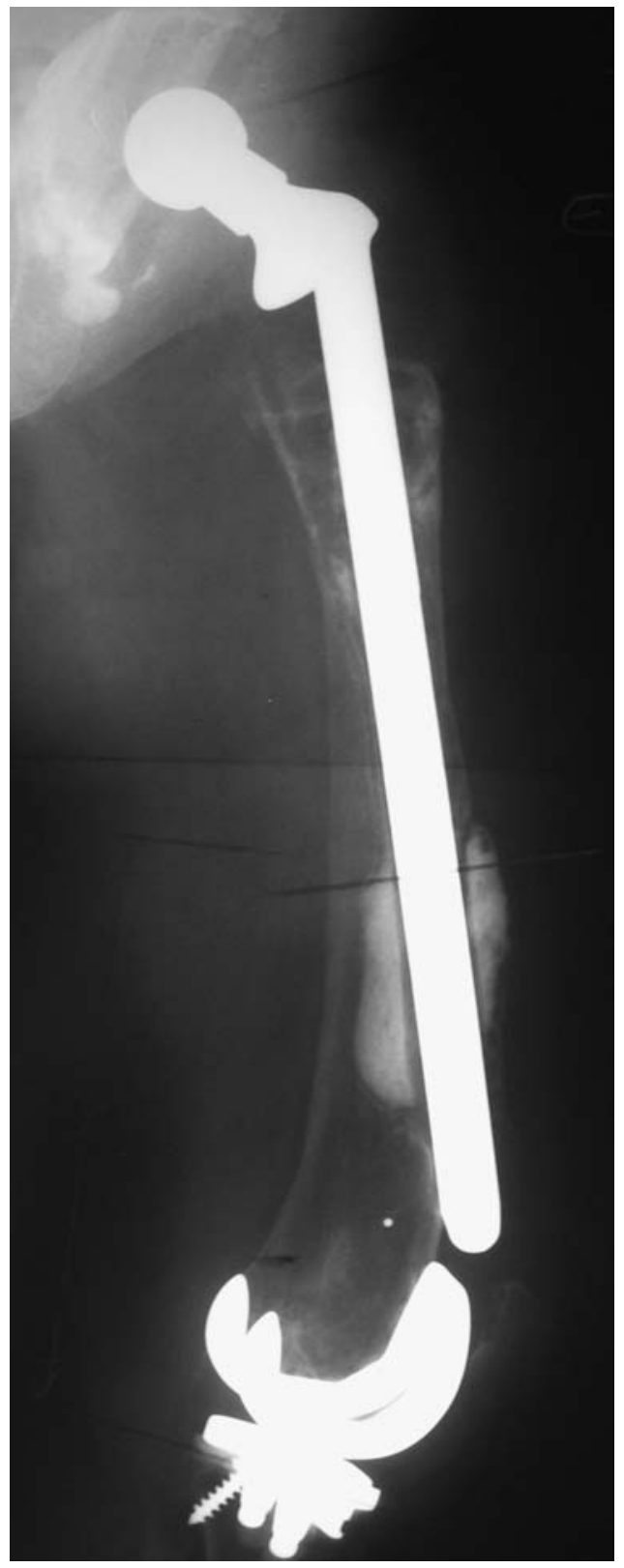

Fig. 2a

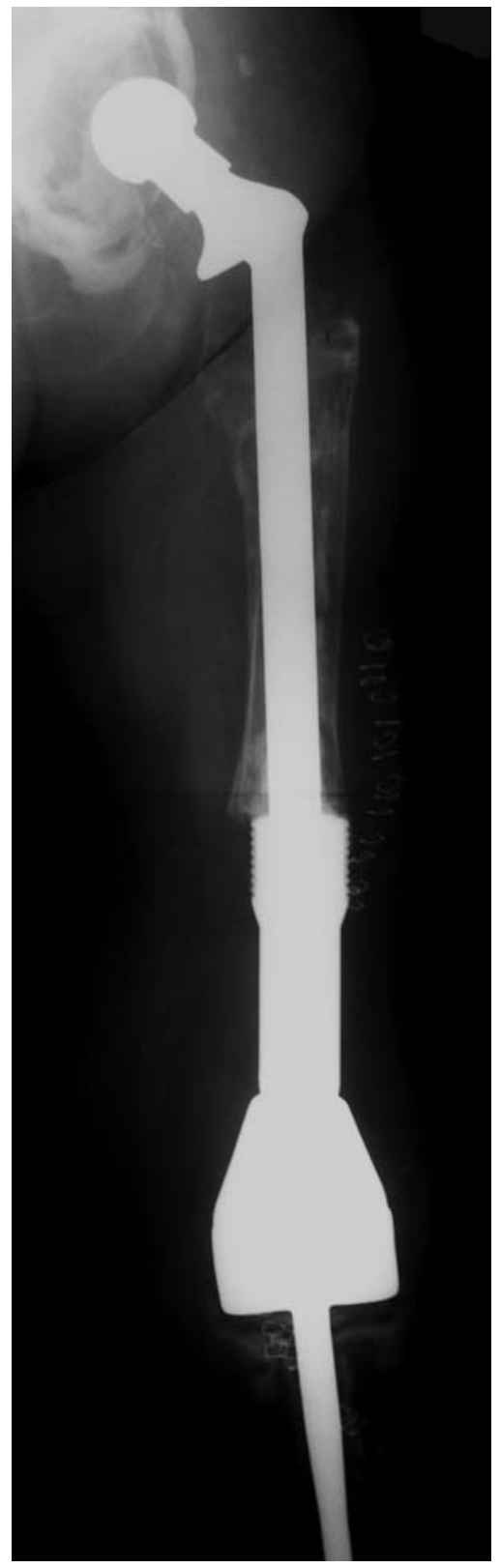

Fig. 2b

Figure 2a - Radiograph of a 69-year-old woman with chronic renal failure who sustained a peri-prosthetic fracture with the long stem of the revision hip prosthesis protruding through the anterior femoral cortex. The patient also had an ipsilateral knee replacement. Figure $2 b$ - Post-operative radiograph after revision with a custom-made distal femoral endoprosthesis, connected to the long stem of the existing total hip replacement using a custom-made cylinder.

\section{Discussion}

Peri-prosthetic fractures below a well-fixed implant, with considerable associated bone loss, are still a largely unsolved problem. ${ }^{12}$ We describe a new technique which has proved to be successful in treating five patients with peri- and subprosthetic fracture in the presence of a wellfixed femoral component. In these patients there were no realistic or appealing options in terms of internal fixation, or standard knee or tumour prostheses, and all patients were immobile before surgery. In our experience older patients generally function poorly after a total femoral replacement. Amputation had been considered in some of the patients before their referral to our unit.

This technique places stresses on the stem of the femoral component, which were not envisaged by the designers, but there were no mechanical failures, loosening or new infections, and no further surgery was required for any reason. One patient was followed up for nine years. We did not 
Table I. Details and results in the five patients

\begin{tabular}{|c|c|c|c|c|c|c|c|}
\hline Case & $\begin{array}{l}\text { Age } \\
\text { (yrs) }\end{array}$ & Gender & Pre-operative diagnosis & $\begin{array}{l}\text { Additional medical } \\
\text { diagnosis }\end{array}$ & $\begin{array}{l}\text { Overlap with new } \\
\text { prosthesis }(\mathrm{cm})\end{array}$ & $\begin{array}{l}\text { Follow-up } \\
\text { period (mths) }\end{array}$ & Outcome \\
\hline 1 & 75 & $\mathrm{~F}$ & $\begin{array}{l}\text { Pathological fracture of } \\
\text { femoral shaft through a lytic } \\
\text { lesion below existing total } \\
\text { hip replacement }\end{array}$ & $\begin{array}{l}\text { Lytic lesion found to } \\
\text { be plasmacytoma }\end{array}$ & 8.2 & 6 & $\begin{array}{l}\text { Mobilising with two sticks; pain } \\
\text { free; no evidence of loosening/ } \\
\text { implant failure or infection }\end{array}$ \\
\hline 2 & 81 & $M$ & $\begin{array}{l}\text { Nonunion of subprosthetic } \\
\text { fracture of femur below } \\
\text { existing revision hip } \\
\text { prosthesis }\end{array}$ & $\begin{array}{l}\text { Rheumatoid arthritis } \\
\text { Paget's disease of femur }\end{array}$ & 7.5 & 36 & $\begin{array}{l}\text { Walks with a frame; no evidence } \\
\text { of loosening/implant failure or } \\
\text { infection; no pain }\end{array}$ \\
\hline 3 & 60 & $\mathrm{~F}$ & $\begin{array}{l}\text { Mid-shaft fracture of femur } \\
\text { between long-stemmed total } \\
\text { knee replacement and } \\
\text { existing total hip } \\
\text { replacement }\end{array}$ & Rheumatoid arthritis & 5.5 & 108 & $\begin{array}{l}\text { Died from unrelated cause. Had } \\
\text { no evidence of loosening/ } \\
\text { implant failure or pain at last } \\
\text { follow-up and walked with one } \\
\text { stick }\end{array}$ \\
\hline 4 & 69 & $\mathrm{~F}$ & $\begin{array}{l}\text { Subprosthetic fracture of } \\
\text { femur with existing long- } \\
\text { stemmed hip prosthesis and } \\
\text { ipsilateral knee prosthesis. } \\
\text { The stem of the hip } \\
\text { prosthesis protruded } \\
\text { through the anterior femoral } \\
\text { cortex }\end{array}$ & Chronic renal failure & 10.0 & 24 & $\begin{array}{l}\text { Evidence of osteolysis around } \\
\text { the proximal femoral } \\
\text { component, but good fixation in } \\
\text { the proximal tibia and no } \\
\text { evidence of loosening of the } \\
\text { acetabular component. Died } \\
\text { from unrelated cause }\end{array}$ \\
\hline 5 & 78 & $\mathrm{M}$ & $\begin{array}{l}\text { Infected nonunion of } \\
\text { subprosthetic fracture } \\
\text { between existing hip and } \\
\text { knee replacements }\end{array}$ & & 6.5 & 60 & $\begin{array}{l}\text { Walks with two sticks without } \\
\text { pain; chronic discharging sinus } \\
\text { requiring twice weekly } \\
\text { dressings. No evidence of } \\
\text { loosening/implant failure }\end{array}$ \\
\hline
\end{tabular}

undertake any biomechanical studies to establish the optimum overlap of the custom-made cylinder, a figure which would vary between hip implants. The mean overlap in our series was $7.5 \mathrm{~cm}(5.5$ to 10$)$. We would not recommend an overlap of less than $5.5 \mathrm{~cm}$. We were surprised at the durability of this technique, given the unusual biomechanical stresses which it must generate.

This technique gave good results in this highly selected group of patients with challenging peri- and subprosthetic fractures of the femur, in which the only conventional option would have been conversion to a total femoral prosthesis, or a very long proximal femoral replacement. These are major undertakings and would require removal of a satisfactory THR.

No benefits in any form have been received or will be received from a commercial party related directly or indirectly to the subject of this article.

\section{References}

1. Kyle RF, Crickard GE 3rd. Periprosthetic fractures associated with total hip arthroplasty. Orthopaedics 1998;21:982-4.
2. Rorabeck CH. Periprosthetic fractures: a problem on the rise. Orthopedics 2000;23: 989-90.

3. Younger SE, Dunwoody J, Duncan CP. Periprosthetic hip and knee fractures: the scope of the problem. Instr Course Lect 1998;47:251-6.

4. Mennen U. The paraskeletal clamp-on plate. Part I: a new alternative for retaining the surgically reduced position of bone fractures. S Afr Med J 1984;66:167-70.

5. Noorda RJ, Wuisman PI. Mennen plate fixation for the treatment of periprosthetic femoral fractures: a multicenter study of thirty-six fractures. Injury 2002;33:47-50.

6. Berend KR, Lobardi AV, Mallory TH, Adams JB, Dodds KL. Total femoral arthroplasty for salvage of end-stage prosthetic disease. Clin Orthop 2004;427:162-70.

7. Fabronic RH, Castagno A, Aguilera AL, Steverlynch AM, Zeballos J. Long-term results of limb salvage with the Fabroni custom made endoprosthesis. Clin Orthop 1999;358:41-52.

8. Freedman EL, Eckardt JJ. A modular endoprosthetic system for tumour and nontumour reconstruction: preliminary experience. Orthopedics 1997;20:27-36.

9. Sierra RJ, Trousdale RT, Pagnano MW. Above-the-knee amputation after a total knee replacement. J Bone Joint Surg [Am] 2003;85-A:1000-4.

10. Brady OH, Garbuz DS, Masri BA, Duncan CP. Classification of the hip. Orthop Clin North Am 1998;30:215-20.

11. Brady OH, Garbuz DS, Masri BA, Duncan CP. The reliability and validity of the Vancouver classification of femoral fractures after hip replacement. J Arthroplasty 2000;15:59-62.

12. Lindahl H, Malchau H, Oden A, Garellick G. Risk factors for failure after treatment of a periprosthetic fracture of the femur. J Bone Joint Surg [Br] 2006;88-B: 26-30. 